\title{
Spondyloepimetaphyseal dysplasia-short limb-abnormal calcification syndrome
}

INSERM

\section{Source}

INSERM. (1999). Orphanet: an online rare disease and orphan drug data base.

Spondyloepimetaphyseal dysplasia-short limb-abnormal calcification syndrome.

ORPHA:93358

Spondyloepimetaphyseal dysplasia-short limb-abnormal calcification syndrome is a rare, genetic primary bone dysplasia disorder characterized by disproportionate short stature with shortening of upper and lower limbs, short and broad fingers with short hands, narrowed chest with rib abnormalities and pectus excavatum, abnormal chondral calcifications (incl. larynx, trachea and costal cartilages) and facial dysmorphism (frontal bossing, hypertelorism, prominent eyes, short flat nose, wide nostrils, high-arched palate, long philtrum). Platyspondyly (esp. of cervical spine) and abnormal epiphyses and metaphyses are observed on radiog raphy. Atlantoaxial instability causing spinal compression and recurrent respiratory disease are potential complications that may result lethal. 